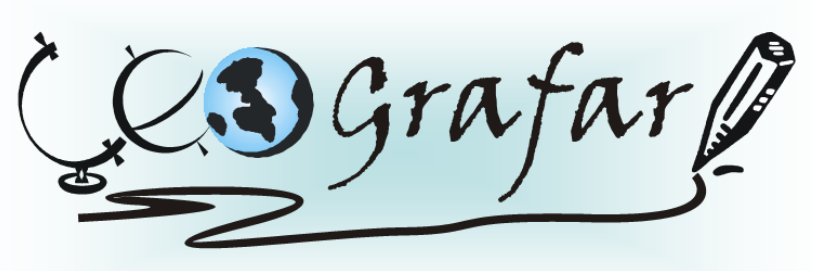

Revista Eletrônica do Programa de Pós-Graduação em Geografia - UFPR

\title{
A FORMAÇÃO DO ESPAÇO DE RONDÔNIA: \\ UMA ANÁLISE DO ZONEAMENTO SÓCIOECOLÓGICO ECONÔMICO E DO USO E COBERTURA DA TERRA
}

\author{
FORMATION OF SPACE RONDÔNIA: \\ AN ANALYSIS OF ECONOMIC AND ECOLOGICAL ZONING USE AND LAND \\ COVER
}

(Recebido em 12.08.2013; Aceito em: 26.06.2014)

Cláudia Pinheiro Nascimento

Doutoranda em Geografia

Universidade Federal do Pará

Belém, PA, Brasil

e-mail: nascimento.cp@gmail.com

Mauricio Silva

Geógrafo, mestre em Engenharia Civil

Agência Nacional de Águas

Brasília, DF, Brasil

e-mail:mauricio.silva@ana.gov.br

Carlos Santos

Prof. Dr. do Departamento de Geografia Universidade Federal de Rondônia

Porto Velho, RO, Brasil

e-mail:herodoto@unir.br

\begin{abstract}
RESUMO
O processo de formação socioespacial de Rondônia é deflagrado, seguindo padrões de ocupação vinculados à exploração de suas reservas naturais e guiado por intervenções governamentais que condicionam as instituições locais, moldando o modo como seu espaço se organiza. Rondônia, portanto, constituiu-se numa nova espacialidade agrícola, trocando sua cobertura de floresta por lavouras e, principalmente, por pastos. As taxas de desmatamento do estado alcançaram seus maiores índices na década de 1990, como efeito inercial, sobretudo, da exploração de suas terras durante as duas primeiras fases da colonização oficial induzida.
\end{abstract}


Surgem então programas como o POLONOROESTE (Programa de Desenvolvimento Integrado para o Noroeste do Brasil) e o PLANAFLORO (Projeto Agropecuário e Florestal de Rondônia) como forma de tentar solucionar os problemas ambientais existentes. Este artigo busca verificar se o PLANAFLORO, por meio do Zoneamento Sócioeconômico e Ecológico de Rondônia continua a ser aplicado e se suas ações apresentam reflexos no sentido de serem detectadas no espaço atual do estado. Para tal, foram utilizadas pesquisas bibliográficas, com o intuito de demonstrar o processo de formação socioespacial de Rondônia, além do apoio metodológico das técnicas de geoprocessamento que permitiram realizar a sobreposição das áreas delimitadas pelo PLANAFLORO com os dados do levantamento do Uso e Cobertura da Terra (TerraClass) desenvolvida pelo INPE (Instituto Nacional de Pesquisas Espaciais). Os dados indicam que o Zoneamento Sócioeconômico e Ecológico de Rondônia apresenta uma metodologia ineficiente na contenção do desmatamento e de usos mais produtivos para a terra.

Palavras-Chave: Zoneamento Ecológico Econômico; Uso e Cobertura da Terra; Formação Socioespacial; Rondônia.

\begin{abstract}
The socio-spatial formation of Rondônia is triggered according to the highest occupancy linked to the exploitation of its natural resources and guided by government interventions that affect local institutions, shaping the way your spatial is organized. Rondônia, therefore, constituted a new spatiality agricultural exchanging their forest cover by crops and mainly by pastures. Deforestation rates in the state reached their highest levels in the 1990s, as inertial effects, especially the exploitation of their lands during the first two phases of official colonization induced. In this phases we see programs like POLONOROESTE (Integrated Development Programme for the North West of Brazil) and PLANAFLORO (Project Agricultural and Forestry Rondônia) as a way of trying to solve environmental problems. This article aims to verify if the PLANAFLORO through the Socio Economic and Ecological Zoning of Rondônia continues to be applied and if their actions have consequences in the sense of being caught in the current scope of the state. For that, we used literature searches in order to demonstrate the process of socio-spatial formation of Rondônia, in addition to methodological support geoprocessing techniques that made possible the overlapping of the areas bounded by PLANAFLORO with survey data of Land Use and Land Cover (TerraClass) developed by INPE (National Institute for Space Research). The data indicate that Socio Economic and Ecological Zoning of Rondônia have an inefficient method in avoiding deforestation or landuse most effective.
\end{abstract}

Keywords: Land Use, Land Cover, Socio-Spatial Formation, Rondônia, Ecologial an Economic Zoning. 


\section{INTRODUÇÃO}

A condição de periferia conferida à Amazônia, vista por uma ótica de análise regional, está associada, ao que parece, ao estabelecimento de atividades extrativistas como função adequada desta no contexto do país.

Juntamente com a exploração dos produtos primários, surge um conjunto de intervenções governamentais, através de diversas instituiçõesi', que se manifestam na forma de leis e programas oficiais, que acabam por interferir nos hábitos e costumes da sociedade local.

Dentro desse contexto, o processo de formação socioespacial de Rondônia é deflagrado, seguindo padrões de ocupação vinculados à exploração de suas reservas naturais e guiado por intervenções governamentais que condicionam as instituições locais, balizando o modo como seu espaço se organiza.

Rondônia, portanto, constituiu-se numa nova espacialidade agrícola, trocando sua cobertura de floresta por lavouras e, principalmente, por pastos. As taxas de desmatamento do estado alcançaram seus maiores índices na década de 1990, como efeito inercial, sobretudo, da exploração de suas terras durante as duas primeiras fases da colonização oficial induzida.

Os ciclos de extração minero-vegetal, pelo qual passou a economia do estado, não implicaram o surgimento de um forte setor de transformação de produtos primários, pois essa etapa econômica de processamento industrial ainda é incipiente.

Em virtude dos efeitos dos ciclos exploratórios, extrativista e agrícola, e da devastação ambiental que o estado passou, políticas de correção passaram a ser implantadas como forma de tentar solucionar os mencionados problemas. Surgem então programas como o POLONOROESTE (Programa de Desenvolvimento Integrado para o Noroeste do Brasil) de acordo com o Decreto n 86.029 de 27 de maio de 1981, e o PLANAFLORO (Projeto Agropecuário e Florestal de Rondônia), cujo objetivo geral era "implantar uma abordagem mais aperfeiçoada para o_manejo, a conservação e o desenvolvimento dos recursos naturais do Estado", em acordo com o Zoneamento Socioeconômico e Ecológico, tratado no Decreto Estadual no 3.782, de 14 de junho de 1988. 
Este artigo busca verificar se o PLANAFLORO, implantado na busca de um aperfeiçoamento para o manejo, conservação e desenvolvimento das reservas naturais do estado, através do Zoneamento Socioeconômico e Ecológico de Rondônia, aprovado em 1992, continua a ser aplicado e se suas ações apresentam reflexos no sentido de serem detectadas no modo como o espaço atual do estado se configura.

Para isso, foi realizada uma pesquisa bibliográfica que busca demonstrar como se deu o processo de formação socioespacial do estado de Rondônia, tentando delinear os modos de apropriação das suas reservas naturais, como também, consequentemente, avaliar os resultados das políticas de correção implementadas.

Além disso, com o apoio metodológico das técnicas de geoprocessamento, realizou-se a sobreposição das áreas delimitadas pelo PLANAFLORO com os dados do levantamento de Uso e Cobertura da Terra (Terraclass), referente ao ano de 2008, desenvolvido pelo INPE (Instituto Nacional de Pesquisas Espaciais).

Em suma, trata-se de uma análise das condições atuais das áreas delimitadas pelo PLANAFLORO, verificando se este cumpriu ou não a sua proposta inicial.

\section{LOCALIZAÇÃO DA ÁREA DE ESTUDO}

O estado de Rondônia está situado na porção Sul da Região Norte do Brasil, inserido na Amazônia Ocidental, conforme figura 01. Possui $237.590,574 \mathrm{Km}^{2} \mathrm{de}$ área territorial, segundo o IBGE, ocupados por uma população estimada de 1.562.547 habitantes no ano de 2010. O estado está subdividido em 52 municípios, tendo como maior cidade, sua capital Porto Velho, com 428.527 habitantes. Destacam-se ainda as cidades de Ji-paraná (116.610hab.) e Cacoal (78.574 hab.) como cidades de maior porte no estado (IBGE, 2010).

Está compreendido entre as latitudes de $7^{\circ} 58^{\prime} \mathrm{S}$ e $13^{\circ} 41^{\prime} \mathrm{S}$ e longitudes $59^{\circ}$ 46' W e 66 48' W. Possui limites com os estados do Amazonas (N), Mato Grosso (L), e Acre (W) e com a Bolívia (S e W) por cerca de 1.000 quilômetros. O clima predominante é o tropical úmido apresentando uma estação seca bem definida entre 
junho e agosto e precipitação média em torno de 2.500 mm/ano (RADAMBRASIL, 1978).

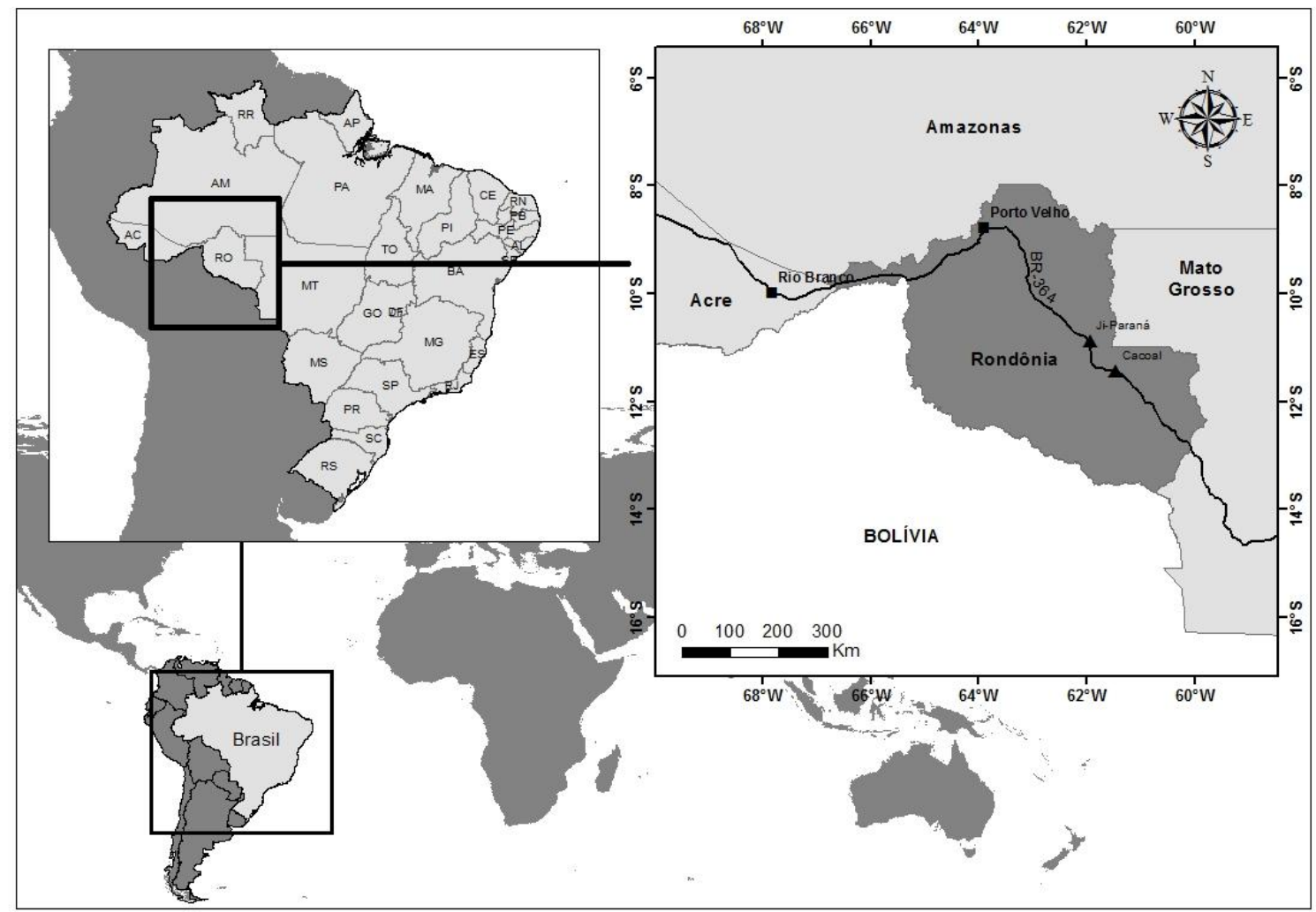

Figura 1. Localização do estado de Rondônia

Fonte: Elaboração Própria

\section{MATERIAIS E MÉTODOS}

A proposta deste artigo é estabelecer uma comparação entre o uso da terra em um momento histórico mais recente e de cobertura completa para o Estado de Rondônia. Sendo assim, adotou-se os produtos criados no projeto TerraClass (INPE, 2011) que buscou classificar o uso da terra em todas as áreas desflorestadas da Amazônia subdividindo-as em 13 classes. O projeto disponibiliza através de seu site todos os polígonos interpretados subdivididos segundo as imagens do satélite Landsat que serviram para a interpretação visual das classes de uso da terra.

Estes polígonos divididos em cenas foram unidos em uma camada de informação através da função Union e recortados através da função Clip utilizando para o recorte o limite do estado de Rondônia disponibilizado pelo IBGE também em seu site. O software utilizado para unir e recortar bem como as demais funções 
espaciais em Sistema de Informação Geográfica foi o ArcGIS Desktop, conforme figura 02.

Além do mapa de uso da terra também foi necessário obter os polígonos de cada zona do Zoneamento Ecológico Econômico, disponibilizado em formato shapefile através do site da Secretaria de Estado de Meio ambiente - SEMA/RO (RONDONIA, 2007).

Ambos os levantamentos apresentam dados em escala compatível de 1:100.000 em Datum SAD69. Dessa forma, utilizou-se a função Union para unir as duas camadas obtendo assim uma camada com a informação do uso da terra e da zona que pertence. A partir desta camada realizou o somatório, através da função Summarize, das áreas de cada uso segundo cada zona, resultando assim na tabela exibida no quadro 4.

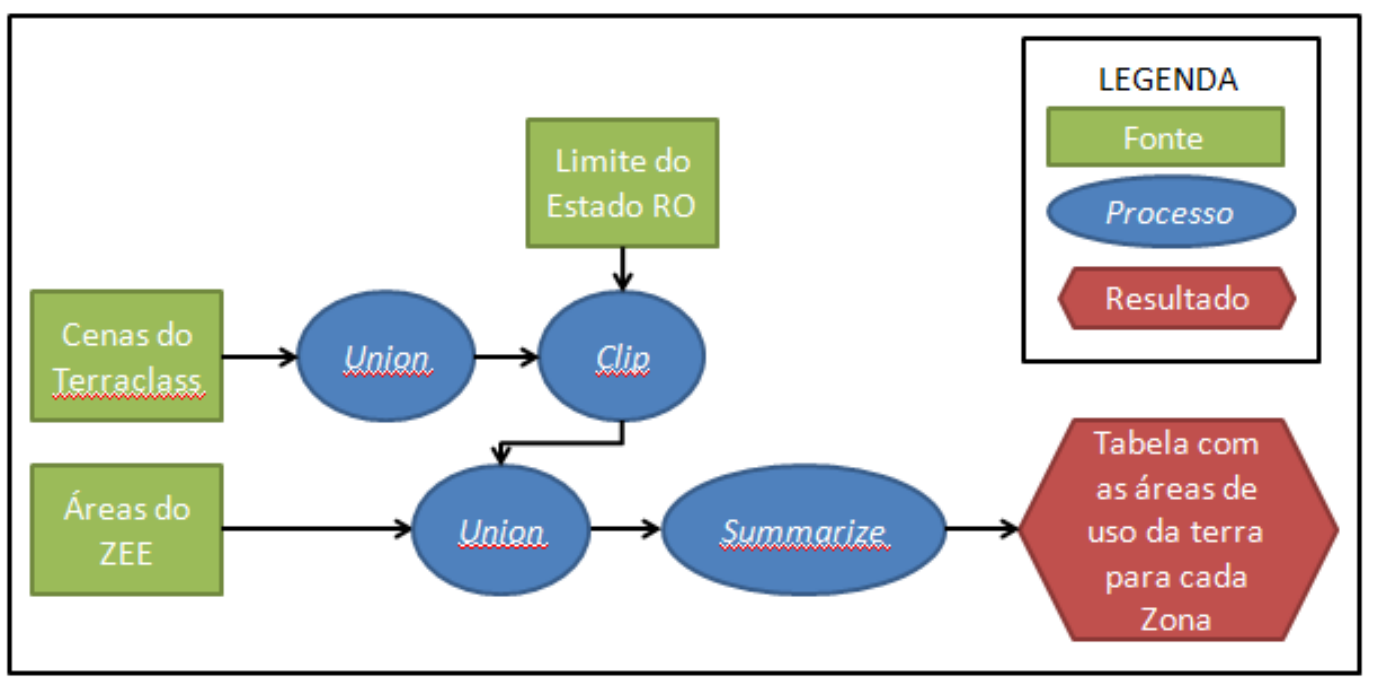

Figura 2. Fluxograma com o método para obtenção dos dados zonais de uso da terra.

Fonte: Elaboração Própria

\section{HISTÓRICO DE OCUPAÇÃO DE RONDÔNIA}

Os povos indígenas foram os únicos ocupantes, por milhares de anos, da região do atual estado de Rondônia, até a chegada dos primeiros europeus no século XVII, com a penetração das bandeiras na busca de ouro, madeiras nobres, especiarias e preação de índios. Diversas foram as expedições que se dirigiram para a região. Em 1650, Raposo Tavares comandando uma expedição alcançou o vale do rio Guaporé (TEIXEIRA e FONSECA, 2002). 
A ocupação da região amazônica esteve associada à implantação dos núcleos missioneiros, que estiveram, sobretudo, vinculados à coleta das chamadas "drogas do sertão" e à preação indígena, visando o confinamento em reduções. Especificamente, no caso do que viria ser Rondônia, a atividade missionária se dá ao longo do Madeira a partir de 1669 (TEIXEIRA e FONSECA, 2002).

Durante os quatro primeiros séculos após o descobrimento, a Amazônia Ocidental ficou isolada do mercado de consumo do país. A borracha foi o produto que incorporou essa parte da Amazônia brasileira ao mercado de bens de consumo do Brasil, atraindo muitos migrantes na busca de novas perspectivas de vida.

Empreendimentos como a construção da Estrada de Ferro Madeira Mamoré (1872-1912), a instalação dos postos telegráficos ao longo do território (1905-1915) e a abertura em 1961 do que seria a atual BR 364, contribuíram para a ocupação das terras do que viria ser Rondônia.

O declínio da extração da borracha amazônica se deu por conta da concorrência com a exploração feita pelos ingleses de modo mais racional na Malásia, com o manejo científico das plantas, contrastando com o empirismo da produção silvestre brasileira, o que levou à ociosidade a recém-construida estrada de ferro Madeira-Mamoré, eventos que causaram grande impacto social em Porto Velho, como, por exemplo, o desemprego (SANTOS, 2007).

Fearnside (2005) afirma que a floresta amazônica brasileira permaneceu intacta até o início da recente modernização brasileira. Principalmente com a implementação de políticas de ocupação, visando a integração da região ao contexto econômico brasileiro, promovidas pelos militares na década de setenta do século passado. Como exemplo, a construção da rodovia Transamazônica em 1970.

Segundo Alves (2001), foi a partir da década de 1970 que o processo de ocupação da Amazônia se acelerou e milhões de hectares de florestas foram derrubados para a criação de pastos, projetos de colonização e reforma agrária.

Sendo assim, os ciclos exploratórios na Amazônia, e especificamente em Rondônia, passaram a ser implantados a partir da década de 1970, quando se inicia a intervenção do Governo Federal na região via diversos projetos de colonização. 


\subsection{A IMPLANTAÇÃO DOS PROJETOS DE COLONIZAÇÃO}

A implantação dos projetos de colonização ocorreu, sobretudo, nas áreas rurais e interioranas do atual estado de Rondônia, principalmente ao longo da BR364. Foi intensificada pela criação em junho de 1970 do Programa de Integração Nacional (PIN), com claras implicações para a Amazônia.

A década de 1970 trouxe grandes transformações para o estado de Rondônia, a ascensão do governo militar associada à necessidade de resolver problemas políticos/econômicos e geopolíticos trouxe como solução a distribuição de terras dirigida pelo Estado (HENRIQUES, 1984).

A seca na região nordeste no ano de 1969/70 acelerou a intervenção do governo federal para viabilizar as políticas de colonização para a Amazônia, promovendo o deslocamento das primeiras levas de migrantes para a região (HENRIQUES, 1984, p. 400).

Essas políticas representaram, por outro lado, uma forma de aliviar as tensões sociais no campo brasileiro, especialmente no agro nordestino, sem que necessariamente se realizasse uma reforma agrária (SANTOS, 2007, p.70) " .

Dentro dos processos de colonização implantados na Amazônia, Rondônia se constituiu com uma particularidade, pois seu processo de colonização foi de natureza totalmente oficial. Os modos de conceber as terras em Rondônia foram a grande empresa capitalista e um novo tipo de campesinato (por ter que considerar o mercado).

Segundo Santos (2007, p.74), o processo colonizador era parte de implantação da modernidade no campo brasileiro, que criaria espacialidades com recursos governamentais, associada a diretrizes urbanizantes, ou seja, associada a uma racionalidade urbana no sentido tecnológico.

A população rural que se deslocou para estas áreas, apesar de manterem traços da agricultura de subsistência, pertence a um conjunto social caracterizado pela presença da cidade, onde as influências externas apresentam-se na obtenção de ferramentas, insumos e até mesmo na alimentação (NASCIMENTO, 2009). 
Essa nova onda migratória traz consigo, novos costumes e hábitos ligados principalmente às cidades, que acabam por se revitalizar em função das novas necessidades trazidas por estes migrantes (NASCIMENTO, 2009).

Esse novo quadro se estabelece pela mudança na origem e perfil dos migrantes. Nos anos de 1960, eram predominantemente nordestinos e voltados basicamente para a agricultura de subsistência, a partir da década de 1970, o fluxo migratório passa a vir, graças à rodovia, principalmente do Centro-Oeste e SulSudeste, dos estados de Paraná, Espírito Santo e Minas Gerais (SANTOS, 2007, p.79).

Segundo Santos (2007), os migrantes que compuseram a leva da década de 1970, principalmente os sulistas, possuíam uma tradição de campesinato, de propriedade familiar da terra; diferentemente dos nordestinos, que culturalmente, dado o latifúndio canavieiro, na zona da mata nordestina, não tinham uma tradição de relação de propriedade com a terra, como já referido acima. Conforme Coy (1988), junto com os migrantes sulistas chegaram empresas do Sul que se apropriaram de extensas áreas de antigos seringais para mineração e especulação imobiliária.

Em Rondônia, a maior concentração de migrantes ocorreu ao longo da BR 364, mas à medida que as terras próximas à estrada foram ocupadas, o movimento foi se interiorizando, causando problemas junto às populações indígenas (SANTOS, 2007).

Neste momento as atividades do INCRA (Instituto Nacional de Colonização e Reforma Agrária) se tornaram decisivas, e concentram-se em dois níveis, a legalização da situação fundiária na área e assentamento dos recém-chegados, que ocorreu através dos PAD (Projeto de Assentamento Dirigido) e PIC (Projeto Integrado de Colonização).

Os projetos de colonização situavam-se, na grande maioria, ao longo da BR 364. Entre 1970/76 o INCRA implantou cinco PICs (Projetos Integrados de Colonização) e dois PADs (Projeto de Assentamento Dirigido) (HENRIQUES, 1984).

Segundo Santos (2007), o tamanho dos lotes variava para cada modalidade de projeto. Nos PICs a área de cada lote era de 100 hectares, padrão instituído para 
a produção agrícola familiar, enquanto os PADs eram de 250; 500; 1000 ha, portanto destinados às monoculturas, como a do cacau.

Como os PICs estavam voltados para a produção agrícola familiar, o INCRA proporcionava toda uma gama de infraestrutura; desde o acesso à terra, implantação de escolas, postos de saúde, estradas vicinais, armazéns para a produção. Já os PADs, deveriam funcionar conforme o perfil dos pretendentes, conforme o grau de capitalização de cada um deles, conforme quadro 01 que indica a distribuição dos projetos de colonização de 1970 a 1978.

Quadro 1. Distribuição dos Projetos de Colonização 1970-1978

\begin{tabular}{|l|c|c|c|c|}
\hline \multicolumn{1}{|c|}{ Projeto } & Criação & Município & $\begin{array}{c}\text { Área } \\
\text { em Ha }\end{array}$ & Lotes \\
\hline \multicolumn{5}{|c|}{ PIC } \\
\hline Ouro Preto & 1970 & Ouro Preto & 512.585 & 4.222 \\
\hline $\begin{array}{l}\text { Sidney } \\
\text { Girão }\end{array}$ & 1971 & Ouro Preto & 60.000 & 635 \\
\hline Ji-Paraná & 1972 & G. Mirim & 486.137 & 4.755 \\
\hline P.A. Ribeiro & 1973 & Cacoal & 293.580 & 3.533 \\
\hline Adolph Rohl & 1975 & Colorado & 407.219 & 3.406 \\
\hline \multicolumn{5}{|c|}{ PAD } \\
\hline Burareiro & 1974 & Jaru & 304.925 & 1.540 \\
\hline Mal. Dutra & 1978 & Ariquemes & 490.178 & 4.675 \\
\hline
\end{tabular}

Fonte: Elaborado pelos autores a partir de dados do INCRA/CCER-1982, adaptado de Silva, (2007, p.83).

Em virtude do grande fluxo migratório, que acabou não sendo absorvido pelos projetos de colonização, o INCRA passou a criar, a partir de 1980, um novo tipo de "Assentamento Rápido". A pretensão deste projeto era acomodar aproximadamente 23 mil famílias que já esperavam ser assentadas, vivendo em regime de parceria ou assalariamento nos lotes já ocupados Além disso, criaram-se os núcleos urbanos de apoio rural (NUAR), em uma área de mais de 1,5 milhão de hectares, que tinha por 
função acolher os migrantes até que conseguissem terra. Os Nuares acabaram dando origem a algumas cidades (SANTOS, 2007).

\subsection{AS POLÍTICAS DE CORREÇÃO E O ZONEAMENTO ECOLÓGICO ECONÔMICO}

A década de 1980 foi marcada por uma gama complexa de problemas e conflitos, fruto da implantação dos projetos de colonização. Os problemas que se estabeleciam eram inúmeros e compreendiam desde a imposição da ideia de propriedade privada, desconhecida dos povos da floresta, até o reconhecimento da fragilidade ecológica presente nas terras da região.

No estado de Rondônia, os problemas de degradação socioambiental são muito presentes e estão associados à implantação dos projetos de colonização, principalmente na década de 1970. Como forma de amenizar estes problemas, foi implantado, em 1981, o programa de Desenvolvimento Integrado para o Noroeste do Brasil (POLONOROESTE, 1979).

O POLONOROESTE foi criado pelo Decreto Federal no 86029 de 27 de maio de 1981 e teve como meta a pavimentação da BR 364, a partir de Cuiabá até Porto Velho, com a intenção de melhorar a integração da região aos centros já modernizados do sul, além de uma estratégia de proteção ambiental e de preservação das comunidades indígenas e extrativistas.

Dentro da primeira etapa do POLONOROESTE, apenas a pavimentação da BR 364 foi efetivada. O suporte à agricultura e à assistência social, bem como as medidas de preservação ao meio ambiente e às populações indígenas não se efetivaram.

Em 1984 o POLONOROESTE sofre uma reformulação na tentativa de superar as distorções entre o estabelecimento do plano e sua efetiva implantação. Diversos problemas foram evidenciados neste momento, como o desaparecimento dos investimentos necessários à criação de crédito para financiamento de culturas perenes, além de ineficiência de gestão e gerenciamento do projeto em virtude da dificuldade de integração entre os órgãos e, por fim, uma imprevista onda de migrantes, entre os anos de 1984/1985, que invadiu áreas ecologicamente impróprias para a agricultura (SANTOS, 2007). 
Grande parte da herança do POLONOROESTE se associa à construção das estradas contempladas no programa e, no caso da BR-364, o seu asfaltamento. Fato que facilitou o acesso à região e que aliada à falta de conhecimento prévio da ecologia local resultou na falta de uma efetiva orientação da ocupação da área.

Essa reformulação do POLONOROESTE, em 1984, deu início a uma nova discussão com o Banco Mundial no intuito de buscar alternativas. Surge daí uma nova proposta de correção das sequelas da colonização dirigida: o "Projeto Agropecuário e Florestal de Rondônia" - PLANAFLORO.

A elaboração da primeira aproximação do Zoneamento Socioeconômico Ecológico (ZSEE), ocorreu entre 1986 e 1988 e apresentou suas ações voltadas a zonas de atuação. Neste momento a escala de trabalho e de representação foi de 1: 1.000 .000 .

Cada zona de atuação estava voltada a usos específicos e dentro de ecossistemas propícios, tendo como objetivo:

a) Reformular as agências locais;

b) Conservar a biodiversidade;

c) Proteger os limites das áreas indígenas;

d) Promover o desenvolvimento de modo integrado entre a colonização agrícola sustentada e os sistemas de manejo florestal;

e) Priorizar os investimentos em infraestrutura e serviços para melhorar áreas já ocupadas e;

f) Adequar a rede institucional local.

O ZSEE em sua primeira etapa estabeleceu seis zonas de atuação definidas como: a zona 1, que foi indicada para intensificação da exploração agropecuária, destinada ao desenvolvimento de atividades agrícolas, pecuárias e agroflorestais; a zona 2, recomendada para o desenvolvimento de atividades agropecuárias e consórcios florestais, priorizando os pequenos produtores organizados em comunidades; a zona 3 , definida como zona ribeirinha sendo recomendado 0 aproveitamento de várzeas e terras firmes marginais aos rios, principalmente o Mamoré, o Madeira e o Machado, para atividades agroflorestais e pesqueiras; a zona 4, destinada ao extrativismo vegetal e de essências florestais como castanhas, 
gomas, óleos, frutos e raízes, mediante manejo de recursos naturais; a zona 5, destinada ao extrativismo madeireiro, também com manejo adequado dos recursos florestais; a zona 6 , definida como zona de ecossistemas frágeis ou muito frágeis, destinadas a preservação e/ou conservação, incluindo as unidades já existentes e as terras indígenas legalizadas, conforme figura 3 (FIERO, 2003).

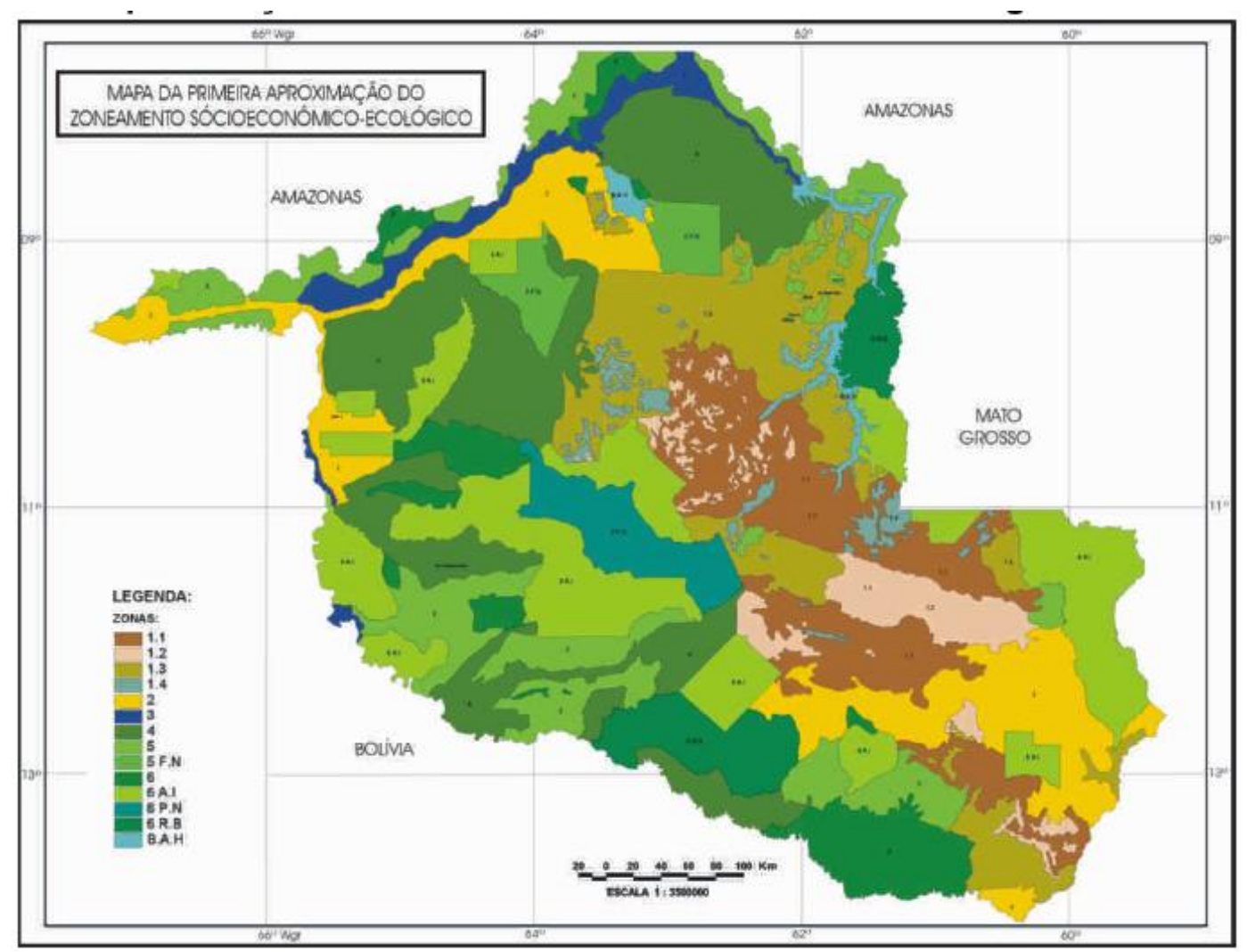

Figura 3. Mapa da primeira aproximação do Zoneamento Socioeconômico - Ecológico de Rondônia Fonte: Governo do Estado de Rondônia, 2007.

Entre 1996 e 1998 foram realizados estudos para subsidiar a elaboração da Segunda Aproximação do Zoneamento Socioeconômico e Ecológico do Estado de Rondônia, instituída pela Lei Complementar № 233, de 06 de junho de 2000, e concluída em 1999.

O objetivo dessa segunda aproximação foi detalhar o conhecimento sobre os meios físico, biológico e socioeconômico. Na segunda aproximação utilizou-se escala de trabalho de 1: 250.000 e de representação de 1:1.000.000, portanto, com maior nível de detalhes. 
O resultado foi a definição de três zonas para todo o estado, sendo a primeira dividida em quatro subzonas, a segunda em duas e a terceira em três, conforme figura 3. Esta divisão teve como base os critérios a seguir.

A zona 1.1 corresponde às áreas com alto nível de ocupação humana e alto potencial natural (solos com boa aptidão agrícola e com baixa susceptibilidade à erosão), onde o uso da floresta natural já não pode ser feito, dado o elevado nível de antropismo, destinando-se à consolidação de atividades socioeconômicas.

A subzona 1.2 corresponde às regiões de médio nível de ocupação humana (potencial social), porém, em processo acelerado de ocupação agropecuária, com conversão da floresta, mas com predomínio da cobertura florestal natural, onde a aptidão agrícola preponderante é regular, a vulnerabilidade natural à erosão é predominantemente de baixa a média, onde foi recomendada a regularização fundiária, mas com controle da exploração florestal e do desmatamento.

A subzona 1.3 comporta as áreas onde predominam a cobertura vegetal natural, cujo processo de ocupação agropecuária é incipiente, com expressivo potencial florestal, com aptidão agrícola predominantemente restrita, médio nível de suscetibilidade à erosão, cuja recomendação é de que as atividades agropecuárias existentes podem ser mantidas, mas sua expansão não deve ser estimulada.

A subzona 1.4 corresponde às áreas com estrutura fundiária definida, mas com restrições naturais ao desenvolvimento de atividades que impliquem a conversão da cobertura vegetal natural, como alta suscetibilidade natural à erosão, estas foram indicadas para recuperação. Nas áreas já desmatadas, recomendou-se a implantação de sistemas de exploração que garantam o controle da erosão, tais como reflorestamento, consórcios agroflorestais e culturas permanentes, de um modo geral.

As áreas onde o nível de ocupação humana é pouco expressivo ou inexpressivo e a suscetibilidade à erosão é elevada, recomendou-se que sejam exploradas em seu estado natural, por meio do manejo florestal. Estas correspondem às zonas 2.1 e 2.2, sendo que esta última é mais vulnerável que a primeira. Além dos aspectos já citados, levou-se em consideração, para definição dessas subzonas, o potencial hídrico, a riqueza da biodiversidade e as áreas onde os estudos indicaram a existência de espécies raras de animais ou vegetais ou beleza cênica. 
$\mathrm{E}$, finalmente, as áreas institucionais, que são as unidades de conservação e terras indígenas já existentes. A subzona 3.1 é constituída por unidades de conservação do uso sustentável, a subzona 3.2, por unidades de proteção integral e a 3.3, por terras indígenas.

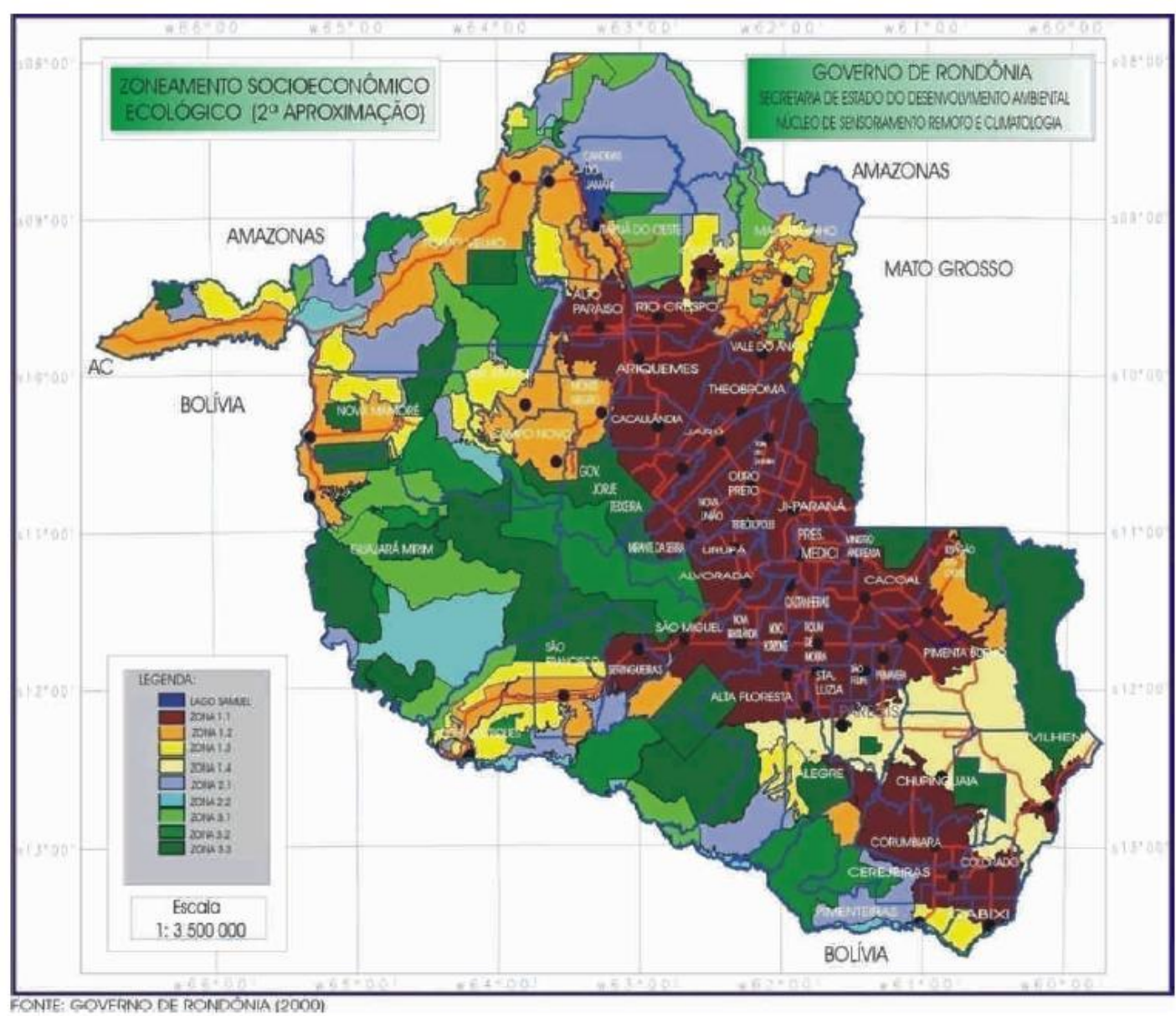

Figura 4. Mapa da segunda aproximação do Zoneamento Socioeconômico Ecológico de Rondônia. Fonte: Governo do Estado de Rondônia, 2007.

\section{O ATUAL USO E COBERTURA DA TERRA NO ESTADO DE RONDÔNIA}

O monitoramento do desmatamento na Amazônia vem sendo realizado pelo INPE (Instituto Nacional de Pesquisas Espaciais) através do PRODES (Programa de Cálculo do Desflorestamento da Amazônia) e apresenta para a Amazônia Legal brasileira, dentro de suas taxas acumuladas de 1988 até o ano de 2008, que cerca de $3.214 .300 .37 \mathrm{Km}^{2}(79,4 \%)$ são domínio de cobertura de floresta, $114.458,64$ km² 
(2,8\%) compreendem a hidrografia e $707.752,35 \mathrm{~km}^{2}$ (17,5\%) compreendem as áreas de desflorestamento acumulado até o ano de 2007 (INPE, 2011).

Com base nessas informações o INPE mapeou o uso e a cobertura da terra para a Amazônia legal brasileira, tendo como base as áreas desflorestadas acumuladas até o ano de 2007, mapeada pelo PRODES denominando este projeto como TerraClass.

O projeto TerraClass restringiu-se a qualificar os $707.752,35 \mathrm{~km}^{2}$ de desflorestamento acumulado até o ano de 2007, mapeado pelo PRODES, considerando onze classes temáticas, segundo quadro 2 .

Quadro 2. Distribuição das áreas correspondentes a cada classe temática mapeada

\begin{tabular}{|l|l|l|l|}
\hline Classe & Área $\left(\mathrm{km}^{2}\right)$ & $\begin{array}{l}\text { Frequência } \\
\text { Absoluta }\end{array}$ & $\begin{array}{l}\text { Frequência } \\
\text { Acumulada }\end{array}$ \\
\hline Pasto Limpo & $335.714,94$ & $46,7 \%$ & $46,7 \%$ \\
\hline $\begin{array}{l}\text { Vegetação } \\
\text { Secundária }\end{array}$ & $150.815,31$ & $21,0 \%$ & $67,6 \%$ \\
\hline Pasto Sujo & $62.823,75$ & $8,7 \%$ & $76,4 \%$ \\
\hline $\begin{array}{l}\text { Regeneração com } \\
\text { Pasto }\end{array}$ & $48.027,37$ & $6,7 \%$ & $83,1 \%$ \\
\hline $\begin{array}{l}\text { Área Não } \\
\text { Observada }\end{array}$ & $45.406,27$ & $6,3 \%$ & $89,4 \%$ \\
\hline Agricultura Anual & $34.927,24$ & $4,9 \%$ & $94,2 \%$ \\
\hline $\begin{array}{l}\text { Mosaico de } \\
\text { Ocupações }\end{array}$ & $24.416,57$ & $3,4 \%$ & $97,6 \%$ \\
\hline Área Urbana & $3.818,14$ & $0,5 \%$ & $98,2 \%$ \\
\hline Mineração & 730,68 & $0,1 \%$ & $98,3 \%$ \\
\hline $\begin{array}{l}\text { Pasto com Solo } \\
\text { Exposto }\end{array}$ & 594,19 & $0,1 \%$ & $98,3 \%$ \\
\hline Outros & 477,88 & $0,1 \%$ & $98,4 \%$ \\
\hline $\begin{array}{l}\text { Desflorestamentos } \\
\text { 2008 }\end{array}$ & $11.458,64$ & $1,6 \%$ & $100,0 \%$ \\
\hline TOTAL & $719.210,99$ & & \\
\hline
\end{tabular}

Fonte: Projeto TerraClass, disponível em: http://www.inpe.br/cra/projetos pesquisas/terraclass.php

Este levantamento digital permite que os dados, devidamente espacializados, possam ser recortados por determinadas áreas de interesse e para o estado de Rondônia, que possui uma área de $237.590,86$ km², apresentando uma qualificação para os $82.947,76 \mathrm{Km}^{2}$ desflorestados até 2008 , conforme quadro 3 . 
Quadro 3. Distribuição das áreas correspondentes a cada classe temática mapeada para o estado de Rondônia

\begin{tabular}{|l|r|r|r|}
\hline \multicolumn{1}{|c|}{ Classe } & Área $\left(\mathrm{km}^{2}\right)$ & $\begin{array}{c}\text { Frequência } \\
\text { Absoluta }\end{array}$ & $\begin{array}{r}\text { Frequência } \\
\text { Acumulada }\end{array}$ \\
\hline Pasto Limpo & 52.871 .31 & $63.7 \%$ & $63.7 \%$ \\
\hline $\begin{array}{l}\text { Vegetação } \\
\text { Secundária }\end{array}$ & 13.349 .15 & $16.1 \%$ & $79.8 \%$ \\
\hline Pasto Sujo & 6.854 .37 & $8.3 \%$ & $88.1 \%$ \\
\hline $\begin{array}{l}\text { Regeneração com } \\
\text { Pasto }\end{array}$ & 5.870 .67 & $7.1 \%$ & $95.2 \%$ \\
\hline Agricultura Anual & 1.440 .42 & $1.7 \%$ & $96.9 \%$ \\
\hline $\begin{array}{l}\text { Desflorestamento } \\
2008\end{array}$ & 949.85 & $1.1 \%$ & $98.1 \%$ \\
\hline Agropecuária & 774.96 & $0.9 \%$ & $99.0 \%$ \\
\hline Área Urbana & 430.64 & $0.5 \%$ & $99.5 \%$ \\
\hline $\begin{array}{l}\text { Área Não } \\
\text { Observada }\end{array}$ & 301.33 & $0.4 \%$ & $99.9 \%$ \\
\hline Mineração & 90.94 & $0.1 \%$ & $100.0 \%$ \\
\hline Outros & 12.32 & $0.0 \%$ & $100.0 \%$ \\
\hline $\begin{array}{l}\text { Pasto com Solo } \\
\text { Exposto }\end{array}$ & 1.80 & $0.0 \%$ & $100.0 \%$ \\
\hline TOTAL & 82.947 .76 & & \\
\hline
\end{tabular}

Fonte: Elaborado pelos autores a partir dos dados do Projeto TerraClass

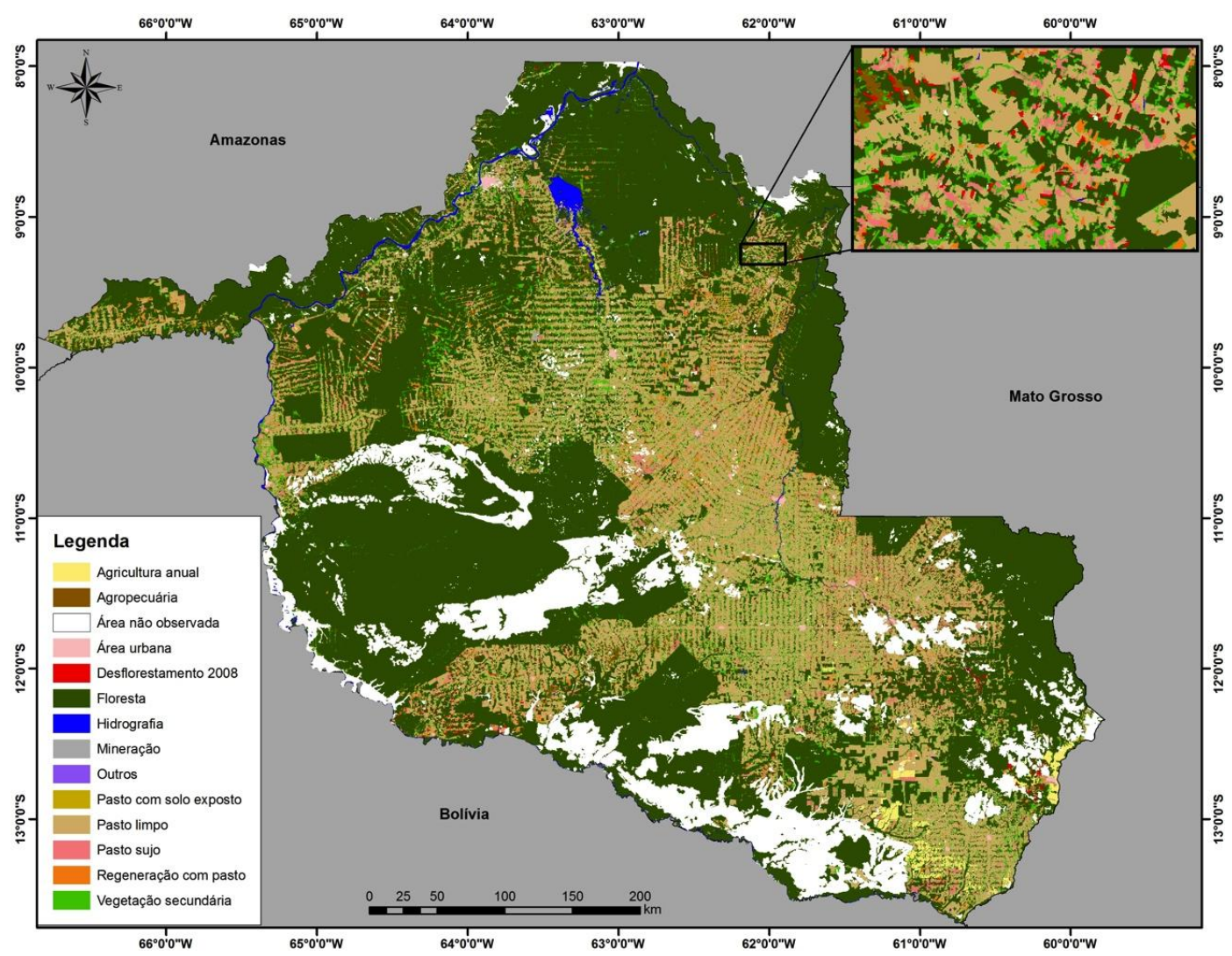

Figura 5. Mapa de Uso e Cobertura da Terra do Estado de Rondônia. Fonte: INPE, 2011 - Projeto TerraClass 


\section{O ATUAL USO E COBERTURA DA TERRA NAS ÁREAS DO ZONEAMENTO.}

Considerando os dados espacializados do TerraClass foi possível gerar uma sobreposição destes com o zoneamento do estado de Rondônia resultando em estatísticas gerais de cada classe de uso e cobertura da terra para cada zona e subzona. Todos os dados estão apresentados nos quadros 04 a 06.

\subsection{Zona 1}

Caracterizada pela lei complementar 233 , artigo $7^{\circ}$, $\S^{1} \stackrel{\circ}{ }$, cujas terras foram utilizadas para diferentes fins, principalmente agropecuário, possuindo graus variáveis de ocupação e de vulnerabilidade ambiental, tem como diretrizes, segundo $\S 2^{\circ}$, estimular o desenvolvimento das atividades primárias em áreas já desmatadas, estimular o manejo sustentado dos recursos florestais remanescentes e aplicação de políticas públicas compensatórias.

Na zona 1, segundo o item III do artigo 7으, obedecerá a seguinte diretriz: "aplicação de políticas públicas compensatórias, visando à manutenção dos recursos florestais remanescentes, evitando a sua conversão para sistemas agropecuários extensivos". Dessa forma a identificação de $749,39 \mathrm{~km}^{2}$ de desflorestamento no ano de 2008 mostra um conflito de uso específico voltado para a conversão de novas áreas, ação contraditória ao que versa a lei complementar do zoneamento e seus instrumentos.

Os remanescentes florestais nativos nesta zona correspondem aos $31,6 \%$ da classe de floresta e $4,1 \%$ de não floresta caracterizadas pelas formações savânicas. Observa-se assim que pouco mais de $35 \%$ estão em situação de manutenção da cobertura original, que se somados aos $9,6 \%$ de vegetação secundária, que caracteriza a recuperação da cobertura da terra, tem-se cerca de $40 \%$ de cobertura florestal ou em recuperação. Considerando que esta zona é composta majoritariamente de propriedades privadas, a zona não apresenta o mínimo de $80 \%$ de cobertura florestal a título de reserva legal e áreas de preservação permanente estabelecidas pelo novo_código florestal brasileiro (lei 12.651/12 art. 12 Inciso I alínea a). 
Quadro 4. Dados de Sobreposição do Uso da Terra em Rondônia com a zona 1 do ZSEE

\begin{tabular}{|l|l|l|l|l|l|l|}
\hline \multicolumn{1}{|c|}{ Classes } & $\begin{array}{l}\text { Subzona } \\
1.1\end{array}$ & $\begin{array}{l}\text { Subzona } \\
1.2\end{array}$ & $\begin{array}{l}\text { Subzona } \\
1.3\end{array}$ & $\begin{array}{l}\text { Subzona } \\
1.4\end{array}$ & \multicolumn{2}{c|}{ Zona 1 } \\
\hline Pasto Limpo & $32.481,60$ & $10.700,26$ & $4.403,02$ & $3.103,40$ & $50.688,27$ & $42,2 \%$ \\
\hline Floresta & $11.669,89$ & $12.042,48$ & $8.180,33$ & $6.047,40$ & $37.940,10$ & $31,6 \%$ \\
\hline $\begin{array}{l}\text { Vegetação } \\
\text { Secundária }\end{array}$ & $6.311,93$ & $3.165,47$ & $1.162,53$ & 831,58 & $11.471,52$ & $9,6 \%$ \\
\hline Pasto Sujo & $3.227,56$ & $1.718,18$ & 748,60 & 507,94 & $6.202,29$ & $5,2 \%$ \\
\hline $\begin{array}{l}\text { Regeneração } \\
\text { com Pasto }\end{array}$ & $2.437,98$ & $1.565,45$ & 691,94 & 249,36 & $4.944,73$ & $4,1 \%$ \\
\hline Não Floresta & $2.094,60$ & 343,16 & 65,76 & $2.390,30$ & $4.893,82$ & $4,1 \%$ \\
\hline Agricultura Anual & $1.312,14$ & 51,89 & 26,00 & 39,72 & $1.429,75$ & $1,2 \%$ \\
\hline $\begin{array}{l}\text { Desflorestamento } \\
\text { 2008 }\end{array}$ & 202,67 & 215,08 & 197,45 & 134,19 & 749,39 & $0,6 \%$ \\
\hline Hidrografia & 189,60 & 319,40 & 71,14 & 8,42 & 588,56 & $0,5 \%$ \\
\hline Agropecuária & 211,52 & 194,40 & 122,28 & & 528,20 & $0,4 \%$ \\
\hline Área Urbana & 238,01 & 176,18 & 3,78 & 6,76 & 424,73 & $0,4 \%$ \\
\hline $\begin{array}{l}\text { Área não } \\
\text { Observada }\end{array}$ & 80,60 & 60,94 & 24,19 & 7,32 & 173,05 & $0,1 \%$ \\
\hline Mineração & 4,43 & 42,99 & & 2,83 & 50,25 & $0,0 \%$ \\
\hline $\begin{array}{l}\text { Outros } \\
\text { Pasto com Solo } \\
\text { Exposto }\end{array}$ & 1,15 & 2,55 & 0,36 & 0,67 & 4,73 & $0,0 \%$ \\
\hline Total (em Km²) & $60.465,44$ & $30.598,46$ & $15.697,38$ & $13.329,89$ & $120.091,17$ & $100,0 \%$ \\
\hline
\end{tabular}

Fonte: Elaborado pelos autores com dados do Terraclass.

Este déficit de áreas florestais vem aumentando, conforme constatação de áreas desflorestadas nos anos de 2008. O montante de áreas necessárias ao atendimento de no mínimo 50\%, considerando a redução permitida pelo novo código florestal em seu artigo 12, §5, é de aproximadamente 12 mil km², ou seja, 120.000 hectares. Com essas dimensões temos as áreas de Pasto Sujo e Regeneração com pasto que somadas atingem cerca de $10 \mathrm{mil} \mathrm{km}^{2}$ que se postas à condição de 
recuperação da cobertura florestal podem se transformar em áreas de vegetação secundária e se aproximar de uma compatibilização da zona ao novo código florestal brasileiro no que tange a diretriz I de manutenção dos remanescentes florestais da área.

\subsection{Zona 2}

Caracterizada pela lei complementar 233, art. 8o, a Zona 2 é composta de áreas de uso especial destinada à conservação dos recursos naturais, passíveis de uso sob manejo sustentável. Dessa forma esta zona está destinada a apresentar em seu estado mais natural ou com alterações de uso sustentável que não impliquem no corte raso da vegetação para sua substituição por outras formas de cobertura para uso.

Os dados recortados para a zona 2 apresentam $89,3 \%$ com coberturas originais representados pelas classes Floresta, Não Floresta (Cerrado) e Hidrografia com uma área de 24.644,77 km², 4.652,50 km² e 625,33 km², respectivamente.

Os 10,7\% remanescentes desta zona estão distribuídos em maior proporção nas classes de Pasto Limpo 4,0\%, Vegetação Secundária 2,8\%, Regeneração com Pasto $1,6 \%$ e Pasto Sujo $1,3 \%$.

A subzona 2.1 tem como prioridade de uso "o aproveitamento dos recursos naturais, mantendo as atividades agropecuárias existentes, sem estímulo a sua expansão" (Art. 18, §3, inciso II, Lei complementar 233), dessa forma, atividades como o desflorestamento não deveriam ser registradas a partir da promulgação da lei de 2000, mas, como registrado pelo TerraClass, em 2008 houve 150,31 km² de desflorestamento, contrariando uma das diretrizes do zoneamento. Na zona 2.2, mais restritiva ainda, em relação ao corte raso, verifica-se $6,40 \mathrm{~km}^{2}$ de desflorestamento.

Na prática foram 15.641 hectares de áreas sendo transformadas para outros usos incluindo o uso não sustentável do recurso madeireiro no ano de 2008, ano em que a taxa de desmatamento foi apresentada como a menor de toda a história de monitoramento do desmatamento que se iniciou em 1988.

Analisando-se os números da zona 2.2 em comparação ao da zona 2.1, a zona 2.2 apresenta-se com uma menor proporção de cobertura e usos conflitivos ao zoneamento. 
Quadro 5. Dados de Sobreposição do Uso da Terra em Rondônia com a zona 2 do ZSEE

\begin{tabular}{|l|c|c|c|c|}
\hline \multicolumn{1}{|c|}{ Classes } & $\begin{array}{l}\text { Subzona } \\
2.1\end{array}$ & $\begin{array}{l}\text { Subzona } \\
2.2\end{array}$ & \multicolumn{2}{c|}{ Zona 2 } \\
\hline Floresta & $18.306,29$ & $6.338,48$ & $24.644,77$ & $73,5 \%$ \\
\hline Não Floresta & $3.356,69$ & $1.295,81$ & $4.652,50$ & $13,9 \%$ \\
\hline Pasto Limpo & $1.225,66$ & 107,40 & $1.333,06$ & $4,0 \%$ \\
\hline $\begin{array}{l}\text { Vegetação } \\
\text { Secundária }\end{array}$ & 797,64 & 136,31 & 933,95 & $2,8 \%$ \\
\hline Hidrografia & 503,40 & 121,93 & 625,33 & $1,9 \%$ \\
\hline $\begin{array}{l}\text { Regeneração com } \\
\text { Pasto }\end{array}$ & 459,06 & 64,58 & 523,64 & $1,6 \%$ \\
\hline Pasto Sujo & 390,80 & 50,30 & 441,10 & $1,3 \%$ \\
\hline $\begin{array}{l}\text { Desflorestamento } \\
\text { 2008 }\end{array}$ & 150,31 & 6,40 & 156,71 & $0,5 \%$ \\
\hline Agropecuária & 147,67 & 6,65 & 154,32 & $0,5 \%$ \\
\hline $\begin{array}{l}\text { Área não } \\
\text { Observada }\end{array}$ & 47,36 & 5,31 & 52,67 & $0,2 \%$ \\
\hline Mineração & 18,31 & 1,37 & 19,68 & $0,1 \%$ \\
\hline Área Urbana & 3,61 & 0,91 & 4,52 & $0,0 \%$ \\
\hline Outros & 1,25 & 0,98 & 2,22 & $0,0 \%$ \\
\hline Agricultura Anual & 0,86 & 0,43 & 1,29 & $0,0 \%$ \\
\hline Total (em Km²) & $25.408,91$ & $8.136,85$ & $33.545,77$ & $100,0 \%$ \\
\hline
\end{tabular}

Fonte: Elaborado pelos autores com dados do Terraclass.

\subsection{Zona 3}

Caracterizada pela lei complementar 233, art. 9o, a zona 3 é composta de áreas institucionais, constituídas por aquelas protegidas de uso restrito e controlado. Em seus artigos $21^{\circ}, 22^{\circ}$ e $23^{\circ}$ estão respectivamente subdivididas as zonas em subzonas destinadas às Unidades de Conservação de uso Direto, de Uso Indireto e Terras Indígenas.

Observa-se que as Terras Indígenas correspondentes à sobzona 3.3 são as que apresentam proporcionalmente as menores áreas de pasto limpo e apresentou em 2008 10,19 km² de desflorestamento.

De maneira geral a situação da zona 3 encontra-se com cobertura original na maior parte de sua área (97\%), demonstrando que seu objetivo principal de conservação tem sido atendido. 
Quadro 6. Dados de Sobreposição do Uso da Terra em Rondônia com a zona 3 do ZSEE

\begin{tabular}{|l|c|c|c|c|c|}
\hline \multicolumn{1}{|c|}{ Classes } & Subzona & Subzona & Subzona & \multicolumn{2}{c|}{} \\
\hline Floresta & $15.467,26$ & $15.445,78$ & $34.271,52$ & $65.184,56$ & $78,7 \%$ \\
\hline Não Floresta & $1.398,60$ & $7.117,79$ & $6.348,58$ & $14.864,97$ & $17,9 \%$ \\
\hline Pasto Limpo & 409,71 & 219,56 & 278,96 & 908,22 & $1,1 \%$ \\
\hline $\begin{array}{l}\text { Vegetação } \\
\text { Secundária }\end{array}$ & 185,31 & 448,14 & 161,65 & 795,10 & $1,0 \%$ \\
\hline Hidrografia & 152,58 & 165,49 & 63,27 & 381,34 & $0,5 \%$ \\
\hline $\begin{array}{l}\text { Regeneração } \\
\text { com Pasto }\end{array}$ & 126,77 & 100,14 & 77,57 & 304,47 & $0,4 \%$ \\
\hline Pasto Sujo & 87,30 & 57,78 & 48,72 & 193,81 & $0,2 \%$ \\
\hline $\begin{array}{l}\text { Desflorestamento } \\
\text { 2008 }\end{array}$ & 28,21 & 44,65 & 15,56 & 88,42 & $0,1 \%$ \\
\hline Agropecuária & 49,12 & 10,60 & 10,81 & 70,52 & $0,1 \%$ \\
\hline $\begin{array}{l}\text { Área não } \\
\text { Observada }\end{array}$ & 25,48 & 5,77 & 10,19 & 41,44 & $0,1 \%$ \\
\hline Mineração & 18,03 & 1,72 & 1,23 & 20,98 & $0,0 \%$ \\
\hline Área Urbana & 4,22 & 0,12 & 0,77 & 5,12 & $0,0 \%$ \\
\hline Outros & 0,02 & 0,45 & 0,93 & 1,40 & $0,0 \%$ \\
\hline Agricultura Anual & 0,01 & & 0,28 & 0,29 & $0,0 \%$ \\
\hline Total (em Km² & $17.952,60$ & $23.617,98$ & $41.290,05$ & $82.860,64$ & $100,0 \%$ \\
\hline
\end{tabular}

Fonte: Elaborado pelos autores com dados do Terraclass.

\section{CONCLUSÃO}

Os dados demonstram que a condição atual do uso e cobertura da terra em Rondônia não tem obedecido os padrões estabelecidos pelo Zoneamento Socioeconômico Ecológico do Planafloro.

O que se verifica é que o Zoneamento Sócio Econômico Ecológico foi uma tentativa de reparar os danos ambientais resultantes da fronteira econômica interna em expansão a partir da década de 1970, e que pretendeu disciplinar as atividades de mineração, pecuária e agricultura nos espaços ao redor das reservas e áreas de proteção indígenas estabelecidas pelo PLANAFLORO.

As reservas ambientais e as áreas de proteção indígenas foram criadas com o intuito de evitar a destruição da floresta remanescente, contudo, esta garantia tem sido mantida somente no papel, a continuidade das práticas de desmatamento (como dados já vistos mostram) tem demonstrado que são nestas áreas onde os maiores crimes ambientais associados à exploração ilegal de madeira, mineração e produção de gado tem sido mais frequentes. 
Os dados acerca do uso atual do espaço de Rondônia vêm corroborar a afirmativa de que o Zoneamento Sócio Econômico Ecológico surgiu como uma tentativa de disciplinar as atividades econômicas já desenvolvidas na região, embora não tenha obtido êxito na busca de conter os danos ambientais pré-existentes. Nesse caso, o ZSEE serviu apenas para garantir áreas de uso menos restritivos decorrentes dos projetos de colonização.

Poder-se-ia lembrar, na discussão do zoneamento em Rondônia, o seguinte depoimento de Manfred Nitsch (2001, p. 19): "É difícil atribuir a expansão da chamada 'fronteira' agrícola, pecuária e mineira ao ZSEE, porque sem ele seguramente também aconteceriam processos similares". Porém, a falta quase total, nas discussões em Rondônia, de argumentos tipo 'vocação', 'vulnerabilidade', 'potencial', 'capacidade de suporte', 'sustentabilidade' e outros, usados nos discursos nacionais e estaduais sobre o ZSEE, parecem indicar que ele não serviu de freio aos desmatamentos e à destruição da floresta. A criação de conflitos abertos com a legislação preservacionista federal pela Lei ํㅜ 233 de 2000 reforça ainda a hipótese de que o ZSEE, nas suas formas atualmente ou segundo a Metodologia em questão praticadas, tenha um viés antiecológico e/ou antidemocrático."

Desse modo, a conclusão que se impõe é que há uma visão tecnocrática que permeia o discurso sobre a Amazônia. Evidente que o discurso oficial fala sempre em preservação, e sempre a enfatizará, porém vivemos no contexto de um capitalismo ainda de caráter selvagem, onde é difícil promover crescimento econômico sem impactos ambientais. Afinal, a mentalidade econômica em voga se pauta pela ênfase no valor de troca e não no valor de uso das reservas naturais. Isto é, a transformação de todo e qualquer patrimônio natural em mercadoria. O paradoxo, no caso, é que se faz sempre a apologia do astronômico valor da biodiversidade amazônica, e, no entanto, o desmatamento avança para alocação da pecuária e da soja. 


\section{BIBLIOGRAFIA}

ALVES, D. S. O processo de desmatamento na Amazônia. Parcerias Estratégias, Brasília: v.12, n. 1, p. 259-275, set. 2001.

BANCO MUNDIAL. Relatório da missão de preparação do Projeto de Desenvolvimento Rural em Rondônia, FAO/Programa de Cooperativas do Banco Mundial. Washington, EUA, 21 de novembro de 1980.

COY, M. Relações entre campo e cidade em áreas de colonização governamental e particular. Os exemplos de Rondônia e do Norte Matogrossense. In: I Congresso de Americanitas, Amsterdam, p. 1-14, 1988.

FEARNSIDE, P. M. Desmatamento na Amazônia brasileira: história, índices e conseqüências. Revista Megadiversidade, Belo Horizonte, v.01, n.01, p. 113-123, 2005.

FIERO - Federação das Indústrias de Rondônia. Rondônia: Perfil e Diretrizes de Desenvolvimento Industrial e de Infraestrutura. Porto Velho: FIERO, 1995.

. Perfil Sócio-Econômico e Industrial. Porto Velho: FIERO, 1997.

. Cadastro de Empresas. Porto Velho, 1997.

Rondônia: perfil socioeconômico industrial. Porto Velho, 2003.

HENRIQUES, M. H. F. da T.. A política de colonização dirigida no Brasil: um estudo de caso, Rondônia. Revista Brasileira de Geografia, Rio de Janeiro, 46, n.03/04, p.393 - 423, 1984 .

- A dinâmica demográfica de uma área de fronteira: Rondônia. Revista Brasileira de Geografia, Rio de Janeiro, v.46, n.03/04, p. 317 356,1985 .

. Os colonos de Rondônia: Conquistas e Frustrações. Revista Brasileira de Geografia, Rio de Janeiro, v.48, n. 01, p. 03 - 42, 1986.

IBGE - Instituto Brasileiro de Geografia e Estatística. Censo Populacional. Rio de Janeiro. 2010.

INPE - Instituto Nacional de Pesquisas Espaciais; EMBRAPA - Empresa Brasileira de Agropecuária. TERRACLASS - Levantamento de informações de uso e cobertura da terra na Amazônia, Sumário Executivo. Setembro, 2011. Disponível em: http://www.inpe.br/cra/projetos pesquisas/sumario executivo terraclass 2008.pdf

MCGRATH, David. Entrevista à Revista Veja. Edição 1828. 12 de novembro de 2003. 
MINISTERIO DO INTERIOR, MINISTÉRIO DA AGRICULTURA, MINISTÉRIO DOS TRANSPORTES. Programa Integrado de Desenvolvimento do Noroeste do Brasil. Área de influência da ligação rodoviária Cuiabá-Porto Velho. Brasília, 1979.

NASCIMENTO, C. P. Cenários da Produção Espacial Urbana de Porto Velho. 2009. 210p. Dissertação (Mestrado em Geografia) - Universidade Federal de Rondônia, UNIR, Porto Velho, 2009.

NITSCH, Manfred. Natureza sem Voz. Avaliação crítica do ordenamento territorial na Amazônia pelo "Zoneamento Ecológico-Econômico". Berlim, 2001.

NORTH, D. Instituiciones, cambio institucional y desempeño econômico. Fondo de Cultura Económica. México, 1993.

PLANAFLORO. Rondônia: Governo do Estado de Rondônia, 1998 - disponível em: http://pesquisa.rondonia.ro.gov.br/index3.html (acessado em 22/02/2010).

RADAMBRASIL. Levantamento de recursos naturais Folha SC.20 - Porto Velho, vol. 16, Rio de Janeiro, 1978.

RONDÔNIA. Governo do Estado. Zoneamento Socioeconômico-Ecológico do Estado de Rondônia: Um Instrumento de Gestão Ambiental a Serviço do Desenvolvimento Sustentável de Rondônia. Porto Velho: SEDAM, 2007.

SANTOS, C. A Fronteira do Guaporé. Porto Velho: Edufro, 2007. 202 p.

SIOLI, H. Amazônia. Fundamentos da Ecologia da Maior Região de Florestas Tropicais. Petrópolis: Vozes, 1991.

TEIXEIRA, M. A. D.; FONSECA, D. R. História Regional: Rondônia. 3. ed. Porto Velho: Rondoniana, 2002. $232 \mathrm{p}$.

(Recebido em 12.08.2013; Aceito em: 26.06.2014)

\footnotetext{
${ }^{\mathrm{i}}$ As instituições são aqui definidas como um conjunto de normas e ações que vão reger as interações entre os indivíduos, conforme Douglas North (1993).

ii A questão embutida nos objetivos da colonização oficial, que se pode deduzir como um corolário distante da famosa Lei da Terra de 1850 é uma tentativa de ser uma alternativa à reforma agrária (SANTOS, 2007, p.70).
} 